\title{
FAKTOR-FAKTOR YANG BERHUBUNGAN DENGAN KEJADIAN ANEMIA PADA IBU HAMIL
}

\author{
Ermawati Edison $^{1}$, Yusriadi Yusriadi ${ }^{2}$ \\ ${ }^{1}$ Akademi Keperawatan Lapatau, Bone, Indonesia \\ ${ }^{2}$ Sekolah Tinggi Ilmu Hukum Pengayoman, Bone, Indonesia
}

\begin{abstract}
ABSTRAK
Penelitian ini bertujuan untuk mengetahui faktor-faktor yang berhubungan dengan kejadian anemia pada ibu hamil. Penelitian ini menggunakan jenis penelitian survey analitik dengan pendekatan cross sectional. Teknik penarikan sampel dengan cara total sampling sebanyak 39 ibu hamil yang mengalami anemia dan tercatat di Rekam Medik. Dari 39 kasus kejadian anemia pada ibu hamil berdasarkan tingkat pendidikan ibu terdapat 30 $(76,9 \%)$ ibu yang memiliki tingkat pendidikan rendah dan $9(23,1 \%)$ ibu yang memiliki tingkat pendidikan tinggi. Berdasarkan umur ibu terdapat $34(87,2 \%)$ ibu yang berada pada kelompok umur (20-35 tahun) dan 5 $(12,8 \%)$ ibu yang berada pada kelompok umur ( $<20$ atau $>35$ tahun). Berdasarkan status ekonomi ibu terdapat $32(82,1 \%)$ ibu yang ststus ekonominya rendah dan $7(17,9 \%)$ ibu yang status ekonominya tinggi. Dari hasil penelitian ini menunjukkan terdapat hubungan yang bermakna antara tingkat pendidikan, umur dan status ekonomi dengan kejadian anemia pada ibu hamil di Puskesmas Biru Periode Januari - September 2012.
\end{abstract}

Kata Kunci: Anemia, Ibu Hamil, Pendidikan, Umur

\section{FACTORS RELATED TO ANEMIA EVENTS IN PREGNANT WOMEN}

\section{ABSTRACT}

This study aims to determine the factors associated with the incidence of anemia in pregnant women. This study uses a type of analytic survey research with a cross-sectional approach. The sampling technique using total sampling was 39 pregnant women who were anemic and recorded in the Medical Record. Of the 39 cases of anemia occurring in pregnant women based on maternal education level, there were 30 (76.9\%) mothers who had a low education level and 9 (23.1\%) mothers who had a higher education level. Based on maternal age there were 34 (87.2\%) mothers in the age group (20-35 years) and 5 (12.8\%) mothers who were in the age group ( $<20$ or $>35$ years). Based on maternal economic status there were $32(82.1 \%)$ mothers with a low economic status and 7 (17.9\%) mothers with high economic status. The results of this study indicate that there is a significant relationship between education level, age and financial situation with the incidence of anemia in pregnant women.

Keywords: Anemia, of Pregnant Women, Education, Age 


\section{PENDAHULUAN}

Anemia pada umumnya terjadi di seluruh dunia, terutama di negara berkembang. Pada kelompok dewasa, anemia terjadi pada wanita usia reproduksi, terutama wanita hamil dan wanita menyusui karena mereka banyak yang mengalami defisiensi zat besi. Secara keseluruhan anemia terjadi pada $45 \%$ wanita di negara berkembang dan 13\% di negara maju (Fatmah, 2008, Hal. $45)$.

Menurut data World Health Organization (WHO) pada tahun 2010, $20 \%$ dari 515.000 kematian maternal di seluruh dunia disebabkan oleh anemia. Di Negara-Negara Association of Southeast Asian Nations (ASEAN) pada tahun 2010 Angka Kematian Ibu (AKI) Indonesia menempati posisi tertinggi yakni 248 per 100.000 kelahiran hidup. Berdasarkan Survey Demografi Kesehatan Indonesia (SDKI) survei terakhir tahun 2007 AKI di Indonesia sebesar 307 per 100.000 kelahiran hidup, meskipun demikian angka tersebut masih tertinggi di Asia.

Upaya untuk menurunkan AKI harus melalui jalan yang terjal. Terlebih kala itu dikaitkan dengan target Millenium Development Goals (MDGs) 2015, yakni menurunkan AKI menjadi 102 per 100.000 kelahiran hidup yang harus dicapai. Waktu yang tersisa hanya tinggal tiga taun ini, tidak akan cukup untuk mencapai sasaran itu tanpa upayaupaya yang luar biasa (www.co.id/whoaki-target-mdgs.online, diakses tanggal 24 September 2012).

Berbagai upaya memang telah dilakukan untuk menurunkan AKI, antara lain melalui penempatan bidan di desadesa, pemberdayaan keluarga dan masyarakat dengan menggunakan Buku
Kesehatan Ibu dan Anak (KIA) dan Program Perencanaan Persalinan dan Pencegahan Komplikasi (P4K), serta penyediaan fasilitas kesehatan Pelayanan Obstetri Neonatal Emergensi Dasar (PONED) di puskesmas pelayanan dan Pelayanan Obstetri Neonatal Emergensi Komprehensif (PONEK) di rumah sakit. Selain itu, direncanakan pula akan diadakannya uji kompetensi bagi seluruh bidan untuk mengetahui kelayakan bidan dalam memberikan pelayanan kesehatan secara komprehensif (www.co.id/whoaki-target-mdgs.online, diakses tanggal 24 September 2012).

Frekuensi anemia pada ibu hamil di Indonesia adalah $70 \%$, ini berarti 7 dari 10 wanita hamil kita menderita anemia gizi besi. Di Indonesia anemia umumnya disebabkan oleh kekurangan zat besi, sehingga dikenal istilah anemia gizi besi. Anemia ini disebabkan oleh kekurangan zat besi, merupakan jenis anemia yang paling sering terjadi selama kehamilan. Penyebabnya kebutuhan zat besi yang meningkat selama kehamilan, kualitas makanan yang tidak memadai atau adanya penyakit kronis. Selain karena kekurangan zat besi dalam darah, anemia dapat pula terjadi karena kombinasi kekurangan besi, asam folat dan vitamin B12. Anemia defisiensi zat besi merupakan masalah gizi yang paling lazim di dunia dan menyangkut lebih dari 600 juta manusia (Wiknjosastro H, 2008, Hal. 23).

Untuk mendeteksi anemia pada kehamilan maka pemeriksaan kadar $\mathrm{Hb}$ ibu hamil harus dilakukan pada kunjungan pertama. Bila kadar $\mathrm{Hb}<11$ gr $\%$ maka ibu dinyatakan anemia dan harus diberi suplemen tablet zat besi $(\mathrm{Fe})$ yang berisi $80 \mathrm{mg}$ besi dan $0,5 \mathrm{mg}$ asam folat, diminum secara teratur 1 tablet/hari 
selama 90 hari berturut-turut, bila kadar $\mathrm{Hb}$ masih $<11 \mathrm{gr} \%$ pemberian tablet zat besi dilanjutkan (Sri Pujiningsih, 2010, Hal. 23).

Di Indonesia prevalensi anemia pada kehamilan masih tinggi yaitu sekitar 40,1\% Survey Kesehatan Rumah Tangga (SKRT 2010). Lautan J dkk. (2010) melaporkan dari 31 orang wanita hamil pada trimester II didapati $23(74 \%)$ menderita anemia, dan $13 \quad(42 \%)$ menderita kekurangan zat besi.

Berdasarkan data yang diperoleh dari Dinas Kesehatan Kabupaten Bone pada tahun 2011 jumlah ibu hamil yaitu 15.960 (98,78\%) orang, $93(3,88 \%)$ orang diantaranya mengalami anemia. Sedangkan jumlah ibu hamil periode Januari-September 2012 yaitu 7.426 $(41,96 \%)$ orang, $89(2,69 \%)$ orang diantaranya anemia.

Menurut data yang diperoleh dari Medical Record (MR) Puskesmas Biru Kabupaten Bone Tahun 2011 ditemukan dari 480 (95\%) ibu hamil yang memeriksakan kehamilannya terdapat diantarannya $31 \quad(3,57 \%)$ ibu yang menderita anemia. Sedangkan pada periode Januari-September 2012 ditemukan dari 345 (63\%) ibu hamil yang memeriksakan kehamilannya terdapat diantaranya $39(3,93 \%)$ ibu yang menderita anemia.

\section{METODE PENELITIAN}

Penelitian ini menggunakan jenis penelitian survey analitik dengan pendekatan cross sectional. Teknik penarikan sampel dengan caratotal sampling sebanyak 39 ibu hamil yang mengalami anemia dan tercatat di Rekam Medik. Analisa univariat dilakukan terhadap setiap variabel dari hasil penelitian. Analisis ini akan menghasilkan distribusi dan persentase dari tiap variabel yang diteliti. Analisa bivariat dilakukan untuk mengetahui hubungan dua variabel (variabel independent dan variabel dependent) yaitu hubungan tingkat pendidikan, umur dan status ekonomi dengan kejadian anemia pada ibu hamil. Untuk melihat hubungan dua variabel tersebut dilakukan uji statistik Chi Square dengan bantuan Computer SPSS versi 17,00.

\section{HASIL DAN PEMBAHASAN}

Pendidikan adalah usaha sadar dan terencana untuk mewujudkan suasana belajar dan proses pembelajaran agar peserta didik secara aktif mengembangkan potensi dirinya untuk memiliki kekuatan spiritual, keagamaan, pengendalian diri, kepribadian, kecerdasan, akhlak mulia, serta keterampilan yang diperlukan dirinya, masyarakat, bangsa dan Negara (Notoadmodjo, 2008).

Pendidikan adalah suatu proses belajar yang berarti di dalam pendidikan itu terjadi proses pertumbuhan, perkembangan atau perubahan ke arah yang lebih dewasa, lebih baik dan lebih matang pada diri individu, kelompok atau masyarakat.

Hasil penelitian menunjukkan bahwa dari 39 kasus anemia ibu hamil pada tingkat pendidikan rendah terdapat $30(76,9 \%)$ ibu hamil yang mengalami anemia sedangkan pada tingkat pendidikan tinggi hanya terdapat 9 $(23,1 \%)$ ibu hamil yang mengalami anemia.

Umur adalah lamanya waktu perjalanan hidup responden di hitung sejak ia lahir sampai dilakukannya penelitian dengan memakai satuan tahun (Soejono, 2007, hal. 67). 
Hasil penelitian menunjukkan bahwa dari 39 kasus anemia ibu hamil pada kelompok umur (20-35 tahun) terdapat $34(87,17 \%)$ ibu hamil yang mengalami anemia sedangkan pada kelompok umur $(<20$ tahun atau $>35$ tahun) hanya terdapat $5(12,82 \%)$ ibu hamil yang mengalami anemia.

Berdasarkan penelitian diketahui bahwa jumlah ibu hamil yang mengalami anemia sebanyak 39 (3,93\%) orang, 30 $(76,9 \%)$ orang diantaranya tergolongan anemia ringan dan $9(23,1 \%)$ orang lainnya tergolong anemia sedang dari 345 kunjungan ibu hamil periode Januari September 2012, sedangkan pada tahun 2011 tercatat $31(3,57 \%)$ orang yang terkena anemia dari 480 kunjungan ibu hamil. Anemia dalam kehamilan adalah kondisi ibu dengan kadar haemoglobin di bawah 11 gr\% (Saifuddin, 2006).

Anemia dalam kehamilan merupakan masalah nasional karena mencerminkan nilai kesejahteraan sosial ekonomi masyarakat dan pengaruhnya sangat besar terhadap kualitas sumber daya manusia (Manuaba, 2010). Anemia yang sering ditemukan pada ibu hamil adalah anemia defisiensi besi yang disebut dengan "potential danger to mother and child" (bahaya potensial bagi ibu dan anak) dan pengaruhnya sangat besar terhadap sumber daya manusia. Oleh karena itu, anemia defisiensi besi ini memerlukan perhatian yang serius oleh semua pihak yang terkait dalam pelayanan kesehatan khususnya pelayanan kesehatan di Indonesia (Manuaba, 2010).

Hasil penelitian ini sejalan dengan penelitian yang dilakukan Yuli Rahmawati (2008) yang menunjukkan $46,3 \%$ responden kejadian anemia pada kehamilannya. Hasil penelitian tersebut juga sama dengan hasil penelitian Agustia Sandra (2010) yang menyatakan jumlah ibu hamil yang mengalami anemia mencapai $74,4 \%$.

Menurut peneliti tingginya kejadian anemia pada ibu hamil disebabkan oleh kurangnya pemahaman ibu hamil tentang dampak dari kekurangan haemoglobin dan rendahnya daya beli ibu hamil untuk memenuhi kebutuhan makanan dan minuman yang mengandung zat besi selama kehamilan.

Hasil penelitian menunjukkan bahwa prevalensi kejadian anemia ringan lebih rendah pada ibu yang memiliki tingkat pendidikan rendah hanya $25 \%$ dibandingkan pada ibu yang memiliki tingkat pendidikan tinggi mencapai $75 \%$, sedangkan prevalensi kejadian anemia sedang lebih tinggi pada ibu yang memiliki tingkat pendidikan rendah mencapai 90,3\% dibandingkan pada ibu yang memiliki tingkat pendidikan tinggi hanya $9,7 \%$.

Berdasarkan hasil analisis uji statistik dengan Chi Square didapatkan nilai $\rho=0,001$ sehingga nilai $\rho=0,001<$ $\alpha=0,05$. Dengan nilai tersebut dapat disimpulkan bahwa Ho ditolak atau terdapat hubungan yang bermakna antara tingkat pendidikan dengan kejadian anemia pada ibu hamil di Puskesmas Biru Kabupaten Bone Periode Januari September 2012.

Hasil penelitian di atas sesuai dengan teori yang menjelaskan bahwa Pendidikan akan berpengaruh pada seluruh aspek kehidupan manusia baik pikiran, perasaan, maupun sikapnya. Semakin tinggi tingkat pendidikan seseorang makin realitas cara berpikirnya serta makin luas ruang lingkup cara berpikirnya termasuk pengetahuan tentang anemia. Tingkat pendidikan 
dapat mendasari sikap ibu dalam menyerap dan mengubah sistem informasi tentang kesehatan (Notoadmodjo, 2008, Hal. 34).

Dari data hasil penelitian dapat disimpulkan bahwa tidak ditemukan adanya kesenjangan antara teori dengan hasil penelitian di lapangan. Selain itu, hasil penelitian ini sejalan dengan penelitian yang dilakukan oleh Yuli Rahmawati (2008), yang menyatakan terdapat hubungan antara tingkat pendidikan ibu hamil dengan kejadian anemia. Demikian juga penelitian yang dilakukan oleh Agustia Sandra (2010), yang menyatakan terdapat hubungan yang bermakna antara tingkat pendidikan dengan kejadian anemia pada ibu hamil.

Pendidikan kesehatan diperlukan pada kelompok ini agar ibu menyadari atau melakukan hal-hal yang dapat memperhatikan kesehatan yang baik untuk dirinya dan keturunan mereka (Notoatmodjo, 2008). Menurut peneliti kejadian anemia pada ibu hamil disebabkan oleh rendahnya tingkat pendidikan ibu hamil sehingga kurang memahami manfaat dan akibat kekurangan zat besi selama kehamilan.

Hasil penelitian menunjukkan bahwa prevalensi kejadian anemia ringan lebih rendah pada ibu yang kelompok umur (20-35 tahun) hanya 25\% dibandingkan pada ibu yang kelompok umur $(<20$ tahun atau $>35$ tahun $)$ mencapai $75 \%$. Sedangkan prevalensi kejadian anemia sedang lebih tinggi pada ibu yang kelompok umur (20-35 tahun) mencapai $93,5 \%$ dibandingkan pada ibu yang kelompok umur $(<20$ tahun atau $>35$ tahun) hanya $6,5 \%$.

Berdasarkan hasil analisis uji statistik dengan Chi Square didapatkan nilai $\rho=0,000$ sehingga nilai $\rho=0,000<$ $\alpha=0,05$. Dengan nilai tersebut dapat disimpulkan bahwa Ho ditolak atau terdapat hubungan yang bermakna antara umur dengan kejadian anemia pada ibu hamil di Puskesmas Biru Kabupaten Bone Periode Januari - September 2012.

Hasil penelitian ini sejalan dengan penjelasan teori yang menjelaskan bahwa umur seseorang yang kurang dari 20 tahun organ reproduksinya belum optimal dan secara psikologi emosi masih labil sehingga apabila terjadi kehamilan mudah terjadi komplikasi yang dapat mengganggu termasuk anemia. Sedangkan umur diatas 35 tahun menunjukkan seseorang mengalami penurunan kemampuan yang dapat mempengaruhi kapasitas kerjanya (Soejono, 2007, hal. 45).

Dengan demikian dapat disimpulkan bahwa tidak ditemukan adanya kesenjangan antara teori dengan hasil penelitian di lapangan. Karena penjelasan anatara teori dan hasil penelitian menunjukkan bahwa semakin tua umur seseorang, kemungkinan untuk mengalami anemia lebih besar dibandingkan dengan seseorang yang berusia lebih muda atau berada pada usia reproduksi. Karena semakin bertambahnya umur seseorang maka semakin sering ia mengalami kehilangan darah (zat besi) pada proses reproduksi atau menstruasi.

\section{KESIMPULAN}

Terdapat hubungan antara tingkat pendidikan dan umur dengan kejadian anemia pada ibu hamil. Diharapkan kepada seluruh petugas kesehatan khususnya bidan untuk meningkatkan kegiatan penyuluhan terkait dengan anemia serta faktor resikonya. Sehingga dengan ini dapat meningkatkan 
pengetahuan ibu dan menurunkan tingkat kejadian anemia pada ibu hamil.

\section{DAFTAR PUSTAKA}

Amiruddin A, Wahyuddin. 2007. Studi kasus Kontrol Faktor Biomedis Terhadap Kejadian Anemia Ibu Hamil Di Puskesmas Pattiro Mampu, http://ridwanamiruddin.wordpress.com, diakses tanggal 24 September 2012.

Anonim. 2009. Diktat Asuhan Kehamilan (Normal).

Aprilya, Sisi. 2010. Hubungan Tingkat Pendidikan dan Status Ekonomi dengan Kejadian Anemia pada Ibu Hamil di Wilayah Kerja UPTDK Puskesmas Desa Cerme Puskesmas Cerme Kecamatan Cerme Kabupaten Bondowoso.

Corwin EJ. 2006. Buku Saku Fatofisiologi. Jakarta : EGC.

Cunningham, F.G. 2005. Obstetri Williams. Edisi 2, Jakarta : EGC.

Dahlan, dkk. 2007. Kamus Istilah Medis. Surabaya : Arkola.

Drs. Stang. 2011. Statistik Dan Metodologi Penelitian. Makassar.

Febryani. 2011. Hubungan Pendidikan Ibu Hamil dengan Kejadian Anemia Di Puskesmas Baringeng Kabupaten Soppeng. http://www.antara.co.id/view/, diakses 26 September 2012.

http://www.depkes. go.id.online, diakses 25 September 2012.

Hoffbrand. 2005. Kapita Selekta Hematologi Edisi 4. Jakarta : EGC.

Hidayat, Abdul Aziz. 2007. Metode Penelitian Kebidanan Teknik Analisis Data Edisi 1. Jakarta : Salemba Medika.
Husaini, dkk. 2005. Studi Nutritional Anemia An Assessment Of Information Compilation For Supporting And Formulating National Policy And Program. Jakarta.

Maimunah, S. 2005. Kamus Istilah Kebidanan. Jakarta : EGC.

Manuaba. 2008. Memahami Kesehatan Reproduksi Wanita. Jakarta : EGC.

Notoatmodjo, Soekidjo. 2008. Metodologi Penelitian Kesehatan. Jakarta : PT. Rineka Cipta.

Proverawati, Atika. 2011. Anemia dan Anemia Kehamilan. Yogyakarta : Nuha Medika.

Pujiningsih, Sri. 2010. Permasalahan Kehamilan. Yogyakarta : Oryza.

Rahmasari, Gartika. 2011. 9 Bulan Penuh Keajaiban Selama Kehamilan. Jakarta Timur : Gudang Ilmu.

Rusmiati. 2009. Asuhan Kebidanan Antenatal. Jakarta : EGC.

Rusram, Mochtar. 2009. Sinopsis Obstetri. Jakarta : Buku Kedokteran.

Saifuddin, Abdul Bahri. 2007. Buku Acuan Nasional Pelayanan Kesehatan Maternal Dan Neonatal. Jakarta : YBPSP.

Sadikin, M. 2006. Biokimia Darah. Jakarta : Widya Medika.

Sandra, Agustia. 2009. Hubungan Pengetahuan dan Ekonomi Ibu Hamil dengan Kejadian Anemia pada Ibu Hamil di Kanagarian Kamang Mudiak Kabupaten Agam.

Saryono. 2010. Asuhan Kebidanan I (Kehamilan). Yogyakarta : Nuha Medika. 
Jurnal Bidan “Midwife Journal” Volume 5 No. 02, Juli 2019 pISSN 2477-3441

eISSN 2477-345X

Wiknjosastro, Hanifa. 2009. Ilmu Kedokteran. Jakarta : YBP-SP.

www.co.id/who-aki-target-mdgs.online, diakses tanggal 24 September 2012.
www.Balita-anda.com/sehat-5, diakses tanggal 23 September 2012.

Yulaikhah. 2010. Asuhan Kehamilan. Jakarta : EGC. 